International Journal of Nursing December 2015, Vol. 2, No. 2, pp. 47-52

ISSN 2373-7662 (Print) 2373-7670 (O nline)

Copyright (c) The Author(s). 2015. All Rights Reserved.

Published by American Research Institute for Policy D evelopment

D O I: $10.15640 /$ ijn.v2n2a6

URL: http:/ / dx.doi.org/ D O I: 10.15640/ ijn.v2n2a6

\title{
Transition to the Matemal Role in Women with Addiction Problems to Psychoactive Substances - Conceptual Map
}

\author{
Carolina Miguel Graça Henniques, Maria Antonia Rebelo Botelho ${ }^{2}$ \\ \& Helena da Conceição Borges Pereira Catarino ${ }^{3}$
}

\begin{abstract}
The transition to motherhood is seen as a phenomenon where are interwoven multiple variables, where the experience of being a mother can be so significant andfull of pleasure, as associated with suffering and unhappiness processes.If we associate this phenomenon, itself multidimensional, the problem of adding the psychoactive substances, the spectrum of its complexity increases, whereas the mother experiences a set of changes associated with pregnancy, childbirth and postpartum, at the same time with their behaviourto addition to psychoactive substances. Looking for the integration of the concepts involved in the problems of transition to the maternal role in women with addition problems to psychoactive substances, we used the conceptual map as a basic tool for the organization of scientific knowledge in the field of study. We conclude from its analysis, that women with addition problems to psychoactive substances, in the process of transition to the maternal role, experience adjustment processes of adaptation and transition, where their past contexts, present and future perspectives converge maternal identity, as the individual characteristics of each woman (self-esteem, personal integrity and self-confidence).
\end{abstract}

Keywords: Women`s Health; Substance Abuse; Maternity Nursing

\section{Introduction}

World leaders recognize that the health of women and children is the key to progress on all development goals (World Health Organization, 2010). The overall strategy for health of women and children emphasizes that a few years to achieve the Millennium Development Goals; global leaders must intensify their efforts to improve women's health, establishing key areas where action is urgent, particularly concerning the integrated provision of health care, especially attending to women and children in vulnerable situations (World Health O rganization, 2010).

Learn become and be a mother, can be so satisfying and important, as painful and unwanted, where the past, present and future contexts may determine how this phenomenon is experienced. The period of pregnancy, the birth of a child and their care, involve an adjustment requires attitudes and behaviours that make possible the assumption of motherhood (Canavarro, 2001). Thus, nurses should know and be aware of the specifics of this process in order to mediate and facilitate it, in order to search for excellence in professional practice, helping women to achieve maximum health potential through programs, specific projects and interventions in vulnerable communities and complex social conditions, from pre-concepcional period, pregnancy and postpartum (Ordem dos Enfermeiros, 2011). As a human science, nursing focuses on human experiences in health-disease process, looking for the understanding of them, as they are experienced by individuals (Meleis, 2011).

\footnotetext{
${ }^{1}$ RN, MSc., PhD student, University of Lisbon \& Nursing School of Lisbon and Adjunct Professor, School of Health Sciences, Polytechnic Institute of Leiria, carolina.henriques@ ipleiria.pt

2 RN, MSc., PhD ., University of Lisbon and Nursing School of Lisbon, Coordinator Professor.

${ }^{3}$ RN, MSc., PhD ., School of Health Sciences, Health Research Unit, Polytechnic Institute of Leiria, Coordinator Professor.
} 
Motherhood is a major life event. Becoming a mother, involves moving from a known reality to a new reality, which means being aware of the transition, preparing for the it and restructuring objectives, behaviours and responsibilities to achieve a new conception and identity itself (Mercer, 2004). Many strategies are used to help in adapting to a new reality maintaining personal integrity (Mercer, 2004), and, this adjustment can be increased or decreased, depending on personal conditions of women, beliefs and cultural attitudes, economic conditions, preparation, knowledge and skills developed, such as the support and community resources (Meleis, et al., 2000).

Nowadays there is some research that has been addressing aspects related to parenting and the construction of maternal and paternal identity, however, the specific aspects inherent in achieving the maternal role in women in vulnerable situations (Mercer, 2004), from pregnancy to the first years of the child's life, are little known. Becoming a mother is an especially critical transition in which the degree of success with which it is carried out has implications not only on the health of the parents themselves, but also on the health and development of their children (Martins, 2008). The transition to parenthood is a model of a transitional situation that affects the whole essence of the human being (Meleis, 2011).

The nursing care that a woman can receive during pregnancy, childbirth and the first year after birth, are central to the healthy development, both for the mother and for the child, and nurses are the health professionals who have the most intense interaction with women on maternity cycle (Mercer, 2004, 1981). We know that clients in transition processes tend to be more vulnerable to the risks, however, considering that the vulnerability is related to the experiences, interactions and environmental conditions that expose individuals to potential risks (Meleis, et al., 2000), the vulnerability associated with the phenomenon of adding to psychoactive substances in women, is amplified when faced with a pregnancy and birth of a child (United Nations Office for Drug Control and Crime Prevention, 2000).

Considering the above, we are interested in questioning about the Lived Experiences of women into motherhood transition when they have added problems to psychoactive substances - From Pregnancy tothe first year of life of the child.

\section{Lived Experience of women face the Transition to Matemal Role}

The International Council of Nurses (2012) ensure gender equality, education and empowerment of women, emphasizing that nurses must have a significant impact on strengthening the capacity of women, especially the most vulnerable, for exercise and increased control over their lives.

The maternal and child health in Portugal have been referred to as an example of good health policies. The experiences lived by women during pregnancy, childbirth, postpartum and early years, seem to be crucial for the knowledge of adjustment, adaptation and transition to motherhood and maternal role, and nurses must be able to understand this process in their specificities and differences in order to identify and provide significant care, based on a philosophy of moral commitment, in which the nursing demand look at humans as experienced subjects (Watson, 2002). Thus, the experience lived; allow us to access the relationship and linkage established between the subject and the world, as pre-reflective and autobiographical reality.

Although the concept of pregnancy and motherhood are still very analyzed by a naturalistic conceptualization (natural experience, common to women, biological predisposition to breed) and essentialist (innate skills to be a mother), they should be explored experienced processes by women (Monteiro, 2005), in which pregnancy refers to the period between the conception and childbirth, and motherhood by a process that begins in the pre-conception period, with no terminus set for been concluded. Thus, motherhood is assumed as a long-term process in which the first years of a child's life, the care needs, the "gift of love, concern, sharing and permanent responsibility", its exercise has a greater visibility (Canavarro, 2001, p.19).

Inserted into the maternity project, pregnancy is understood as the period where cognitively rehearse roles and maternal tasks, and can started or not the prenatal child bonding process. Restructuring up relations to the inclusion of a new member in the family, maternity experience is multiple and variable, depending largely on the meaning assigned to it by those who experience (Canavarro, 2001), with the purpose to achieve the maternal role (Mercer, 2004), this means, the process of attaching or be connected to the child, based on interaction and development that occurs over time, during which the mother binds the child and acquires competence in the care tasks that the role involves. 
The change to the personal status in which the mother experiences a sense of harmony, confidence and competence in the way she plays the role, is the final step in achieving it,, reflectingon the identity of the maternal role (Rubin, 1984), represented in the ability to see herself in the mother's role, that is, the process inwhich individuals make sense of itself (Monteiro, 2005).

Understanding the phenomenon of pregnancy and motherhood as periods of development and transition, these arecharacterized by the need to solve specific developmental tasks, associated with the change processes, implying, therefore, the need for reorganization (Canavarro, 2001; Chick \& Meleis, 1986). The developmental tasks of motherhood have different resolution times. Ranging from woman to woman, They e can sometimes overlap or blend , however, occur normally as follows: Acceptance of pregnancy; Acceptance of the reality of the fetus; Reassessment and restructuring of the relationship with parents, Reassessment and restructuring of the relationship with the spouse/ partner; Baby acceptance as a separate person ; Reassessment and restructuring of their own identity (to integrate the maternal identity); Reassessment and restructuring of the relationship with the other children, if they exist (Canavarro,2001).

\section{The Transition to the Matemal Role in Women with Problems of Psychoactive substances}

When we focus on women with addition problems to psychoactive substances (United Nations Office for D rug Control and Crime Prevention, 2000), we easily realized that the process of achieving the maternal role, as a transition process, it is a highly complex phenomenon, in which intersect multiple factors associated to person, the environment that surrounds it and the health-disease processes, being present experiences, interactions, and environmental conditions that expose these women to a position of vulnerability with more risks (Meleis, et al., 2000). According to studies by several authors (Roberts \& Pies, 2011; Velez et al., 2004; Yamaguchi et al., 2008), the addict woman had an unfortunate childhood, in which dominated the neglect and the physical and psychological abuse.

During the process of motherhood, the woman acquires her own personality as the mother, in which the concepts of self-esteem and self-confidence seem to be crucial for the achievement of the maternal role (Mercer, 2004), and in the world lived of these women coexists simultaneously a past, a present and a future in which human life is a "continuous in time and space" (Watson, 2002, p.86). On the other hand, the environment that surrounds her implies a mutual accommodation, wherein tensions/conflicts and factors such as social support, stress, family functioning, among others, influence the achievement of the maternal role (Mercer, 2004).

Thus, the pregnancy, if preceded by an adaptive project, can be in essence a period of trial and testing. We will say that the nine months are a period of testing, connection, anxiety, fantasies and reflections, that allow the maternity project build and consolidate (Bjørg et al., 2007; Canavarro, 2001). In the wake of conception, pregnancy and motherhood can only be understood as dynamic processesof construction and development. Being a mother, is thus understood not as something that is inscribed in the genes, not an inherent or an instinctive process, but a construction.The addict woman in phase of consumptions, the pregnancy arises, in most cases, as a surprise, because most of the times this is not planned. Its identification is usually late, due to long periods of amenorrhea that are characteristic in prolonged use of opiates. Therefore, the chronology of conception is often poorly defined, diluting in the precariousness of perceptionof own body and of the constraints that the dependence requires.

A systematic review of the literature focused on experiences of women face the transition to the maternal role when they have problems in addition to psychoactive substances (Henriques, Botelho, Henriques \& Vaz, 2014) has allowed us to understand that the life contexts (family, social, affective and violence) in which these women move are complex and central to construction of maternal identity of these women.

According to Frazão et al. (2001), all these factors cannot be translated as a synonym for rejection of pregnancy or "no desire" of it. The feelings of tenderness and desire to be mothers can exist in these women; however, often disturbed and unable to belived in its fullness, by her own conscience that it wasn't the right time, or because of consumption and the anxiety that is caused because of the fear they have that the drug could cause problems in herbaby; fear of malformations or the neonatal withdrawal syndrome. On the other hand, the economic difficulties or lifestyle, conditioned by consumption, can also contribute to limit the maternal performance in the women. 
The systematic review of the literature focused on the experiences of women face the transition to the maternal role when they have added problems to psychoactive substances (Henriques, Botelho, Henriques \& Vaz, 2014) allows us to understand the contexts of life (family, social, affective and violence) in which these women move are complex and central to the construction of maternal identity of these women. The unexpected maternal role is experienced with resignation, but glimpsed the possibility of change and perspective for the future. The maintenance of consumption or the lack thereof, are part of the addition of these women experience, largely marked by social stereotypes regarding the performance of maternity and invisibility for the healthcare team.

In spite of all the problems around the woman with problems of adding to psychoactive substances, the crisis represents both danger and opportunity. On the one hand there is the dangerof further disintegration, disorganization and mismatch, but, on the other hand, is an opportunity to obtain a new level of integration and maturation. The woman, in general, in a crisis situation, becomes more vulnerable and accessible to help, so, pregnancy and motherhood can be considered as a good time for the rehabilitation and treatment of addition and for the resolution of some personal difficulties.

During the period of change, the woman with problems of adding to psychoactive substances, in transition to the maternal role, acquire new knowledge and skills. If on one hand can cause feelings of loss, also reflectingsome difficulties, on the other hand, can be be enjoyable and hulling changes to this as human being. This model refers to an "ecological transition", which occurs when the position orsituation of the person in the environment ecological is changed, as a result of a change of paper, environment or both (Chick \& Meleis, 1986), and face the phenomenon under study may be facing a process of high complexity. Understanding that the nurses take care of people that experienced transitions, anticipate transitions or complement the act of transition in terms of the changes in the health status, inter-relations, in expectations or in capacities (Meleis \& Trangenstein, 1994), the nurse helps individuals find meaning in their lives, promoting self-regulation, the choice and self-determination in making health/ disease (Watson, 2002).

The transition process wrapped in process pregnancy, labour and delivery, postpartum period and first few months of life of the children, in this conceptual framework (Figure 1), is related to the fact that the transition could be caused by a voluntary change and/ or expected or, on the contrary, occur in an uncontrolled way unwanted and unexpected (Chick \& Meleis, 1986). Depending on the social and cultural context in which it occurs, and in accordance with the stage of the life cycle to which it refers, it is acknowledged that the transition refers to a significant change in the lives of these women, through the change and redefinition of roles and statuses (transition developmental, situational and health-disease), as a result of stimuli and new knowledge, which may have as a result the change in behaviour and a different definition of the self in social context (Chick \& Meleis, 1986).

From the lived experiences individuals transform perspectives and act changes (Parse, 1998) and the knowledge of them, nurses access a unique knowledge, enabling a meaningful health care attentive to perspectives of people and their needs in the health human experience (Newman, Sime \& Corcoran-Perry, 1991). 


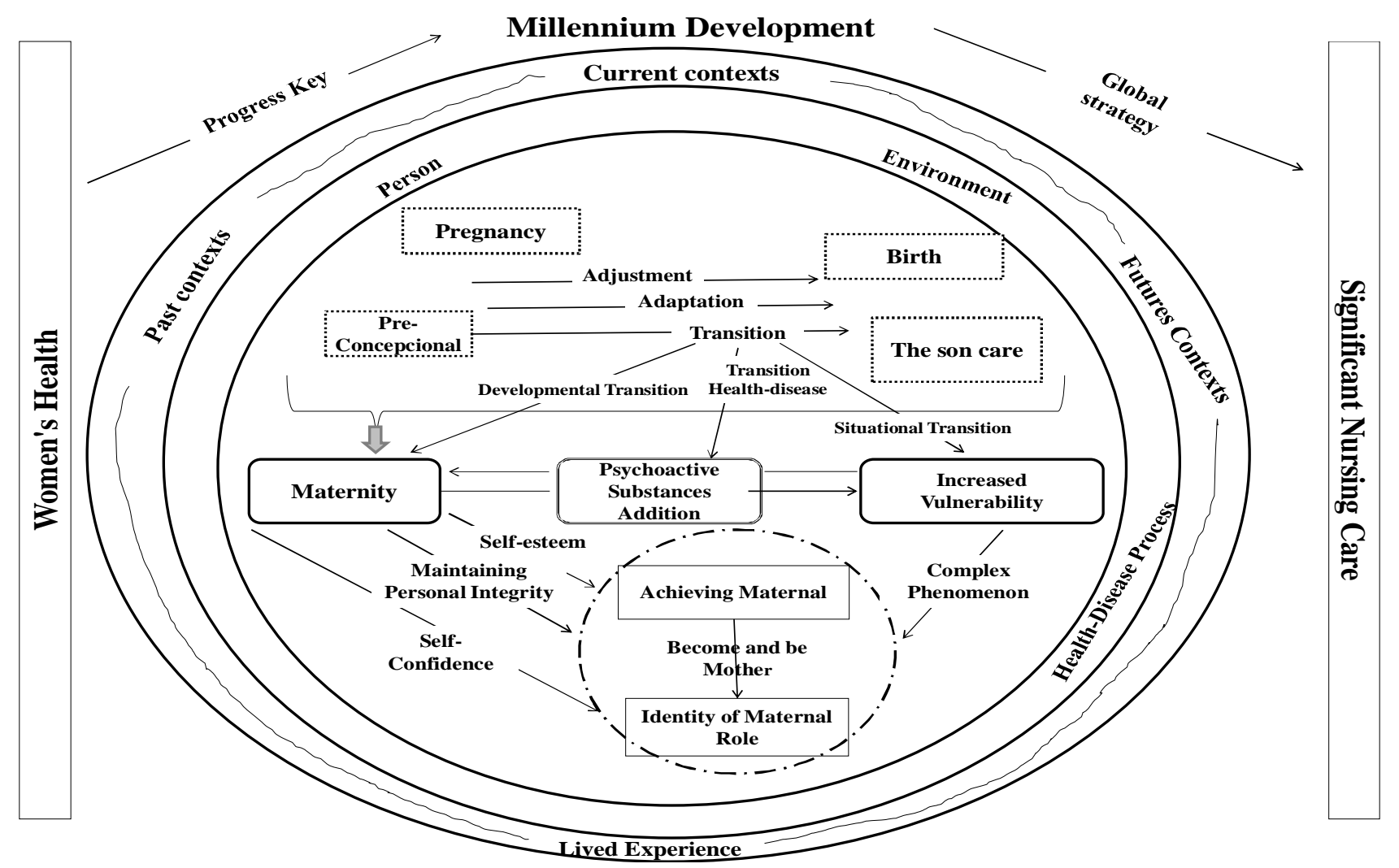

\section{Conclusions}

Figure 1: Conceptual Map

In maternity intertwined multiple conditions and contexts that seem to determine how it is constructed and experienced. Sustained in a process of adjustment, adaptation and transition, from pre-concepcional period, through pregnancy, birth and caring for the child, the motherhood is of distinctive features, in that each woman how to be single, resizes their life contexts (past-present-future).

The problematization presented here emerges from the observation of clinical practice in nursing women with adding problems of the psychoactive substances in the period of pregnancy, childbirth, puerperium and first year of life of the children, as well as the achievement of narrative review of the literature.

Implications for Practice:It seems to us therefore, be crucial the need to develop of intervention strategies in nursing in particular face specific problems in study, both in either at the level of prenatal consultations, units of hospitalization (delivery room and postpartum units) and community settings (family health centers and care facilities in the community).For this to happen, nurses mustfirst seeking to know how the transition to the maternal role is narrated, lived and experienced by these women, so that they can develop therapeutic programs, projects and significant care to them 


\section{References}

Bjørg H., Morten L. \& Elin R. (2007). Substance abuse in pregnant women. Experiences from a special child welfare clinic in Norway. BMC PublicHelth 7 (322). doi:10.1186/ 1471-2458-7-322

Canavarro,M. (2001). Gravidez e maternidade: Representações e tarefas de desenvolvimento. In: Canavarro, M. (Ed.), Psicdoga da Gravidzz eda Materidade(pp. 17-49). Coimbra: Q uarteto Editora.

Chick, N. \& Meleis, A. (1986). Transitions: A nursing concern. In: Chinn, P. (Ed.). Nursingrenchmoddogy (pp. 237257). Boulder, CO : Aspen Publication.

Frazão, C., Pereira, E., Teles, L. \& Amaro, F. (2001). Mulher toxicodapendente e o planemento familiar, a gravidez e a matemidade Lisboa: Fundação Nossa Sra $\mathrm{a}$ Bom Sucesso.

Henriques, C., Botelho, M., Henriques, M. \& Vaz D. (2015). Systematic review of experiences into motherhood transition felt by women undergoing substance abuse treatment. Mitteilungen Klostemeaburg 65 (1), 396-411.

International Council of Nurses (2012). Women'shealth Position Statement. [O nline] Available: www.icn.ch

Martins, C. (2008). Transiçãopara a Parentalidade Programa de D outoramento em Enfermagem: Revisão Sistemática da Literatura. Universidade de Lisboa, Lisboa.

Meleis, A. \& Trangenstein, P. (1994). Facilitating transitions: re-definition of the nursing mission. NursingOutlok, 42(6), 255-259.

Meleis, A. (2011). Theretical Nursing Dedopmet and Progess Philadelphia, PA: Williams \& Wilkins.

Meleis, A., Sawyer, L., Im, E., Messias, D., \& Schumacher, K. (2000). Experiencing transitions: An emerging middle range theory. AdvanresinNursingSaience 23(1), 12-28.

Mercer, R. (1981). A theoretical framework for studying factors that impact on the maternal role. Nursing Reserch, 30(2), 73-77.

Mercer, R. (2004). Becoming a Mother Versus Maternal Role Attainment. Jaumal of NursingSdhdarship 36(3), $226-232$.

Monteiro, R. (2005). O QueDizemAsMães Mulhees Trabalhadbrasesuas Experiendas Coimbra: Q uarteto Editora.

Newman, M., Sime, A. \& Corcoran-Perry, S. (1991). The Focus of the Discipline of Nursing. Advances in Nursing Science. Aspen Publishers, 14(1). In: Polifroni, E. \& Welch, M. (1999). Pespetives an Philosqphy of Saiencein Nursing An Histarical and Contemporary Anthdogy. Philadelphia: Lippincott.

O rdem dos Enfermeiros (2011). Regulamento dos Padrões deQualidadedos Cuidados Espeializados em Enfemagem deSaúde Matema, Obstérica eGinedóǵca [O nline] Available: www.ordemenfermeiros.pt.

Parse, R. (1998). TheHuman BecomingSchod of Thaught California: Thousand $O$ aks.

Roberts, S. \& Pies, C. (2011). Drug Use During Pregnancy Becomes a Barrier to Prenatal Care. Matemal and Child HealthJoumal, 15, 333-341. doi: 10.1007/ s10995-010-0594-7

Rubin R. (1984). Matemal Idantityand theMatemal Experience New Y ork: Springer.

United Nations O ffice for D rug Control and Crime Prevention (2000). DemandReetuction A Glossary of Temes ODCCP Studies on Drugs and Crime - Guidelines. [O nline] Available: http:// www.unodc.org/ pdf/ report_2000-1130 1.pdf

Velez, M., et al. (2004). Parenting knowledge among substance abusing women in treatment. Jaumal of SubstanceAbuse Treatment, 27, 215 - 222.

Watson, J. (2002). Enfermagem Ciênia Humana eCuidar. Uma Teria deEnfemagm Loures: Lusociência.

World Health O rganization (2010). Gldbal Strateey for Womens and Childens Helth United Nations Secretary-G eneral. Ban Ki-Moon.

Yamaguchi, E., et al. (2008). D rug abuse during pregnancy. Reista dePsiquiatria Clínica, 35, 44-47. 